\title{
Erratum to: Chemical quality of leachates and enzimatic activities in Technosols with gossan and sulfide wastes from the São Domingos mine
}

Erika S. Santos ${ }^{1,2}$ - Maria Manuela Abreu ${ }^{2}$ - Felipe Macías $^{3}$ - Amarílis de Varennes ${ }^{2}$

Published online: 30 December 2015

(C) Springer-Verlag Berlin Heidelberg 2015

Erratum to: J Soils Sediments

DOI 10.1007/s11368-015-1068-8

In the published version of this article, Table 3 was incorrect.

The following represents the correct Table 3 :

The online version of the original article can be found at http://dx.doi.org/ 10.1007/s11368-015-1068-8.

$\triangle$ Maria Manuela Abreu manuelaabreu@isa.utl.pt

1 Centro de Investigação em Ciências do Ambiente e Empresariais, Instituto Superior Dom Afonso III, Convento Espírito Santo, 8100-641 Loulé, Portugal

2 Instituto Superior de Agronomia, Universidade de Lisboa, Tapada da Ajuda, 1349-017 Lisboa, Portugal

3 Departamento de Edafología y Química Agrícola, Facultad de Biología, Universidad de Santiago de Compostela, Campus Universitario Sur, 15782 Santiago de Compostela, Spain 
Table 3 Concentrations of anions in leachates from Technosols and gossan wastes - assay 1 (Mean \pm SD; $n=3)$ collected at time zero ( 0 ) and after 3 $\left(1^{\circ}\right)$ and $9\left(2^{\circ}\right)$ months of incubation

\begin{tabular}{|c|c|c|c|c|c|c|c|c|}
\hline \multirow[t]{2}{*}{ Anion } & \multirow[t]{2}{*}{ Sampling } & \multicolumn{7}{|l|}{ Assay 1} \\
\hline & & GW & GA12 & GA30 & GC12 & GC30 & GAC12 & GAC30 \\
\hline \multirow{3}{*}{$\begin{array}{l}\text { As } \\
(\mu \mathrm{g} / \mathrm{L})\end{array}$} & 0 & $0.7 \pm 0.1^{\mathrm{bcd}}$ & $1.3 \pm 0.7^{\mathrm{bc}}$ & $0.7 \pm 0.6^{\mathrm{bcd}}$ & $1.2 \pm 0.2^{\mathrm{bc}}$ & $1.4 \pm 0.1^{\mathrm{b}}$ & $<0.3^{\mathrm{cd}}$ & $7.6 \pm 0.2^{\mathrm{a}}$ \\
\hline & $1^{\circ}$ & $8.9 \pm 5.7^{\mathrm{ab}}$ & $5.7 \pm 3.6^{\mathrm{b}}$ & $17.1 \pm 6.0^{\mathrm{a}}$ & $14.9 \pm 0.4^{\mathrm{a}}$ & $12.1 \pm 5.2^{\mathrm{a}}$ & $8.1 \pm 3.3^{\mathrm{ab}}$ & $6.9 \pm 5.6^{\mathrm{ab}}$ \\
\hline & $2^{\circ}$ & $9.3 \pm 1.7^{\mathrm{b}}$ & $21.0 \pm 9.3^{\mathrm{b}}$ & $20.9 \pm 9.3^{b}$ & $25.0 \pm 7.2^{\mathrm{b}}$ & $76.6 \pm 8.9^{\mathrm{a}}$ & $11.0 \pm 3.8^{\mathrm{b}}$ & $51.8 \pm 24.5^{\mathrm{a}}$ \\
\hline \multirow{3}{*}{$\begin{array}{l}\mathrm{Cl}^{-} \\
(\mathrm{mg} / \mathrm{L})\end{array}$} & 0 & $44.4 \pm 6.4^{\mathrm{c}}$ & $120.0 \pm 13.2^{\mathrm{b}}$ & $196.1 \pm 38.2^{\mathrm{a}}$ & $95.2 \pm 29.9^{\mathrm{b}}$ & $230.7 \pm 20.1^{\mathrm{a}}$ & $79.2 \pm 18.4^{\mathrm{b}}$ & $110.6 \pm 4.4^{\mathrm{b}}$ \\
\hline & $1^{\circ}$ & $39.1 \pm 8.6^{\mathrm{bc}}$ & $56.0 \pm 6.5^{\mathrm{bc}}$ & $108.3 \pm 40.6^{\mathrm{a}}$ & $35.1 \pm 3.5^{\mathrm{c}}$ & $75.9 \pm 18.1^{\mathrm{ab}}$ & $47.3 \pm 20.9^{b c}$ & $66.7 \pm 21.9^{\mathrm{bc}}$ \\
\hline & $2^{\circ}$ & $20.0 \pm 10.4^{\mathrm{b}}$ & $54.0 \pm 2.5^{\mathrm{a}}$ & $77.5 \pm 22.9^{\mathrm{a}}$ & $44.1 \pm 2.4^{\mathrm{a}}$ & $50.9 \pm 12.0^{\mathrm{a}}$ & $48.3 \pm 25.8^{\mathrm{a}}$ & $64.7 \pm 14.2^{\mathrm{a}}$ \\
\hline \multirow{3}{*}{$\begin{array}{l}\mathrm{NO}_{3} \\
(\mathrm{mg} / \mathrm{L})\end{array}$} & 0 & $12.3 \pm 2.0^{\mathrm{c}}$ & $101.7 \pm 25.8^{\mathrm{b}}$ & $88.2 \pm 25.3^{\mathrm{b}}$ & $56.4 \pm 12.3^{\mathrm{b}}$ & $303.5 \pm 92.2^{\mathrm{a}}$ & $74.3 \pm 17.0^{\mathrm{b}}$ & $70.7 \pm 20.2^{\mathrm{b}}$ \\
\hline & $1^{\circ}$ & $10.7 \pm 3.3 b^{c}$ & $21.0 \pm 12.6^{\mathrm{abc}}$ & $25.4 \pm 10.8^{\mathrm{ab}}$ & $16.0 \pm 3.1^{\mathrm{abc}}$ & $32.4 \pm 3.3^{\mathrm{a}}$ & $7.0 \pm 1.5^{\mathrm{c}}$ & $33.0 \pm 18.1^{\mathrm{a}}$ \\
\hline & $2^{\circ}$ & $45.3 \pm 10.8^{\mathrm{a}}$ & $11.0 \pm 10.8^{\mathrm{b}}$ & $8.7 \pm 1.9^{b}$ & $13.3 \pm 6.1^{\mathrm{b}}$ & $6.3 \pm 1.6^{\mathrm{b}}$ & $10.5 \pm 7.2^{\mathrm{b}}$ & $10.1 \pm 1.7^{\mathrm{b}}$ \\
\hline \multirow{3}{*}{$\begin{array}{l}\mathrm{PO}_{4} \\
(\mathrm{mg} / \mathrm{L})\end{array}$} & 0 & $4.3 \pm 0.8^{\mathrm{a}}$ & $4.2 \pm 0.1^{\mathrm{a}}$ & $4.1 \pm 0.1^{\mathrm{a}}$ & $4.2 \pm 0.1^{\mathrm{a}}$ & $4.7 \pm 1.0^{\mathrm{a}}$ & $0.1 \pm 0.04^{\mathrm{b}}$ & $0.03 \pm 0.03^{\mathrm{b}}$ \\
\hline & $1^{\circ}$ & $0.4 \pm 0.3^{\mathrm{bc}}$ & $0.6 \pm 0.5^{\mathrm{bc}}$ & $1.3 \pm 0.8^{\mathrm{ab}}$ & $1.0 \pm 0.3^{\mathrm{bc}}$ & $2.1 \pm 0.9^{\mathrm{a}}$ & $0.1 \pm 0.05^{\mathrm{c}}$ & $0.9 \pm 0.5^{\mathrm{bc}}$ \\
\hline & $2^{\circ}$ & $0.1 \pm 0.1^{\mathrm{c}}$ & $0.8 \pm 0.1^{\mathrm{a}}$ & $0.3 \pm 0.3^{\mathrm{c}}$ & $1.3 \pm 0.4^{\mathrm{a}}$ & $0.9 \pm 0.3^{\mathrm{a}}$ & $0.6 \pm 0.2^{\mathrm{ab}}$ & $0.4 \pm 0.1^{\mathrm{bc}}$ \\
\hline \multirow{3}{*}{$\begin{array}{l}\mathrm{SO}_{4} \\
(\mathrm{mg} / \mathrm{L})\end{array}$} & 0 & $171.4 \pm 24.9^{\mathrm{cd}}$ & $654.9 \pm 268.8^{\mathrm{ab}}$ & $582.9 \pm 156.5^{\mathrm{b}}$ & $395.3 \pm 34.7^{\mathrm{cd}}$ & $875.0 \pm 103.1^{\mathrm{a}}$ & $347.6 \pm 40.9^{\mathrm{cd}}$ & $531.3 \pm 100.2^{\mathrm{bc}}$ \\
\hline & $1^{\circ}$ & $127.5 \pm 21.0^{\mathrm{b}}$ & $271.8 \pm 75.7^{\mathrm{a}}$ & $274.5 \pm 73.1^{\mathrm{a}}$ & $102.7 \pm 21.4^{\mathrm{b}}$ & $209.1 \pm 99.8^{\mathrm{ab}}$ & $116.4 \pm 28.6^{\mathrm{b}}$ & $285.5 \pm 81.9^{\mathrm{a}}$ \\
\hline & $2^{\circ}$ & $139.0 \pm 17.7^{\mathrm{c}}$ & $247.0 \pm 43.9^{\mathrm{a}}$ & $193.9 \pm 21.3^{\mathrm{abc}}$ & $162.9 \pm 8.6^{\mathrm{bc}}$ & $151.5 \pm 38.3^{\mathrm{bc}}$ & $194.1 \pm 73.5^{\mathrm{abc}}$ & $224.0 \pm 48.7^{\mathrm{ab}}$ \\
\hline
\end{tabular}

Different letters in data from the same row indicate significant differences $(p<0.05)$

GW: gossan wastes (control); GA12 and GA30: Technosol containing GW and AgW + AW + RW at 12 and $30 \mathrm{~g} / \mathrm{kg}$; GC12 and GC30: Technosol containing $\mathrm{GW}$ and $\mathrm{AgW}+\mathrm{CW}+\mathrm{RW}$ at 12 and $30 \mathrm{~g} / \mathrm{kg} ;$ GAC12 and GAC30: Technosol containing $\mathrm{GW}$ and $\mathrm{AgW}+\mathrm{AW}+\mathrm{CW}+\mathrm{RW}$ at 12 and $30 \mathrm{~g} / \mathrm{kg}$. $A g W$ : agriculture wastes; $A W$ : residue from the liquor distillation of $A$. unedo fruit; $C W$ : residue from liquor distillation of $C$. siliqua fruit; $R W$ : rockwool used for strawberry crops 